\title{
Physician and pharmacist satisfaction and clinical needs for the real-time medication surveillance program in South Korea
}

\author{
Sun Mi Shin ${ }^{1,2}$, Hong-Ah Kim¹, Inmyung Song ${ }^{3}$, Ha-Lim Jeon ${ }^{2}$ and Ju-Young Shin² ${ }^{*}$
}

\begin{abstract}
Background: Since December 2010, a nationwide real-time medication surveillance program has been implemented in Korea to prevent potential adverse drug reactions. Our goal was to evaluate physicians' and pharmacists' satisfaction and clinical needs for the medication surveillance program in Korea.

Methods: Both web- and paper-based surveys were conducted using a structured questionnaire among 1164 physicians and pharmacists from May 23, 2014 to August 11, 2014. The survey consisted of questions about the participant's satisfaction with the medication surveillance program, clinical usefulness, clinical need for the medication surveillance program, and sociodemographic characteristics. Multivariate ordinal logistic regression was performed to investigate the factors influencing satisfaction levels with the medication surveillance program.

Results: We analyzed data from 1120 respondents, including 503 physicians and 617 pharmacists. Overall, $63.1 \%$ of the respondents were satisfied with the medication surveillance program. Pharmacists were more satisfied with the program than were physicians (69.1\% vs. 55.6\%; adjusted odds ratio, 2.13 ; $95 \%$ confidence interval, 1.65-2.76). Among the respondents, $77.8 \%$ cited a decrease in therapeutic duplication to be a major improvement resulting from the medication surveillance program, $82.6 \%$ considered the drug-drug interaction information useful, and $48.7 \%$ suggested that the program should include information on liver or kidney disease-drug interaction.

Conclusions: Overall, $63.0 \%$ of physicians and pharmacists were satisfied, and a decrease in therapeutic duplication was regarded as the most beneficial component. Further improvements by considering clinical needs of physicians and pharmacists will be needed to increase satisfaction.
\end{abstract}

Keywords: Medication surveillance, Healthcare providers, Satisfaction, Clinical needs, Survey

\section{Background}

Inappropriate drug use can cause adverse drug reactions (ADRs), influence public health, and increase medical expenditures because of unnecessary hospital admissions [1]. For use as a tool to prevent inappropriate drug use, the medication surveillance program (so-called Drug Utilization Review) is a structured, concerted effort to evaluate prescription drug use according to pre-determined standards [2]. Its purpose is

\footnotetext{
*Correspondence: shin.jy@skku.edu

${ }^{2}$ School of Pharmacy, Sungkyunkwan University, 2066, Seobu-ro, Jangan-gu, Suwon, Gyeonggi-do 16419, South Korea

Full list of author information is available at the end of the article
}

to continuously improve the quality of pharmacotherapy by evaluating the appropriateness of prescribed drugs, dosages, administration periods, and quality-of-life attributable to medications [3]. Although details are different from country to country, the program usually addresses issues, such as drug-drug interactions, drug-disease interactions, drug-patient precautions, and drug dosage modifications [4]. The medication surveillance program can ensure the standard quality of pharmacotherapy and safe drug use by reducing the risk of abuse, underand over-use of medications, and preventing ADRs. Furthermore, the medication surveillance program can reduce variation in patient care among prescribers and

(c) The Author(s). 2019 Open Access This article is distributed under the terms of the Creative Commons Attribution 4.0 International License (http://creativecommons.org/licenses/by/4.0/), which permits unrestricted use, distribution, and 
regions by standardizing drug therapy and reduce medical care costs attributable to unnecessary drug use [5].

The development of a national drug database for medication surveillance began in earnest when the Ministry of Health and Welfare of Korea announced a list of drug-drug interactions and age contraindication drugs in 2004 [6]. However, since 2005, the Korea Ministry of Food and Drug Safety (MFDS) has been in charge developing and announcing the drug lists. In December 2010, the computerized real-time medication surveillance system was established and operated by the Health Insurance Review and Assessment Service (HIRA). The Korea Institute of Drug Safety and Risk Management (KIDS), launched in April 2012, took the role of actively developing a drug database for the medication surveillance program. Since then, the type of surveillance has become more diverse by including not only drug-drug interaction, age and pregnancy contraindications but also therapeutic duplication, dosage advisements, and administration period advisements to prevent duplicative use and overuse of medications and as a result cast a wider and more secure net for drug safety (Fig. 1).

In Korea, when a physician writes a prescription, the information is transmitted to the HIRA and checked in real time through a concurrent system. The prescription is compared to the patient's medication history and a list of suspended drugs. If it is determined to have any safety issue, the prescriber receives a warning on the computer screen within $0.5 \mathrm{~s}$. Once having received a message, the prescriber can change the prescription or proceed with the original prescription by entering the reason for the override. The pharmacist that dispenses the prescribed medication undertakes the same process and double checks the prescription. If given an alert, the pharmacist can choose to change the prescription or proceed to dispense the prescribed medication. According to the report published by the HIRA in 2018, the medical surveillance system was established in $99.7 \%$ of all medical institutions and pharmacies and used by $97.7 \%$ of these [7].

The US and European countries that initiated medication surveillance programs earlier experienced alert fatigue, which refers to the phenomenon of habitually overriding pop-up alerts because of frequent occurrences of clinically insignificant, minor alerts [8-11]. This situation is concerning as it can defeat the purpose of the surveillance that was established for patient safety. Diagnosing this problem necessitates evaluating the level of satisfaction with the medication surveillance among healthcare professionals and understanding the inconveniences experienced because of this surveillance program. The scope of the medication surveillance program provided in Korea is narrower than that in other countries because of a lack of information on drug allergies and renal disease precautions $[8,9]$. To maximize the usefulness of the medication surveillance program, we need to understand what more is needed by the clinical practice, as well as to prioritize areas of the greatest need. Therefore, the goals of this study were to evaluate physicians' and pharmacists' satisfaction levels with the medication surveillance program, because they are the main users of the surveillance services, and to investigate the areas where improvement is needed. In addition, because physicians and pharmacists use somewhat different user interfaces and see patients under different circumstances, we hypothesized that they will have different responses regarding their prescription checking processes and the surveillance service performance. Hence, we compared satisfaction and clinical needs with respect to the program between physicians and pharmacists.

\section{Methods}

\section{Questionnaire development}

We developed a structured questionnaire to investigate the level of satisfaction with the medication surveillance program and to identify the areas of additional need for

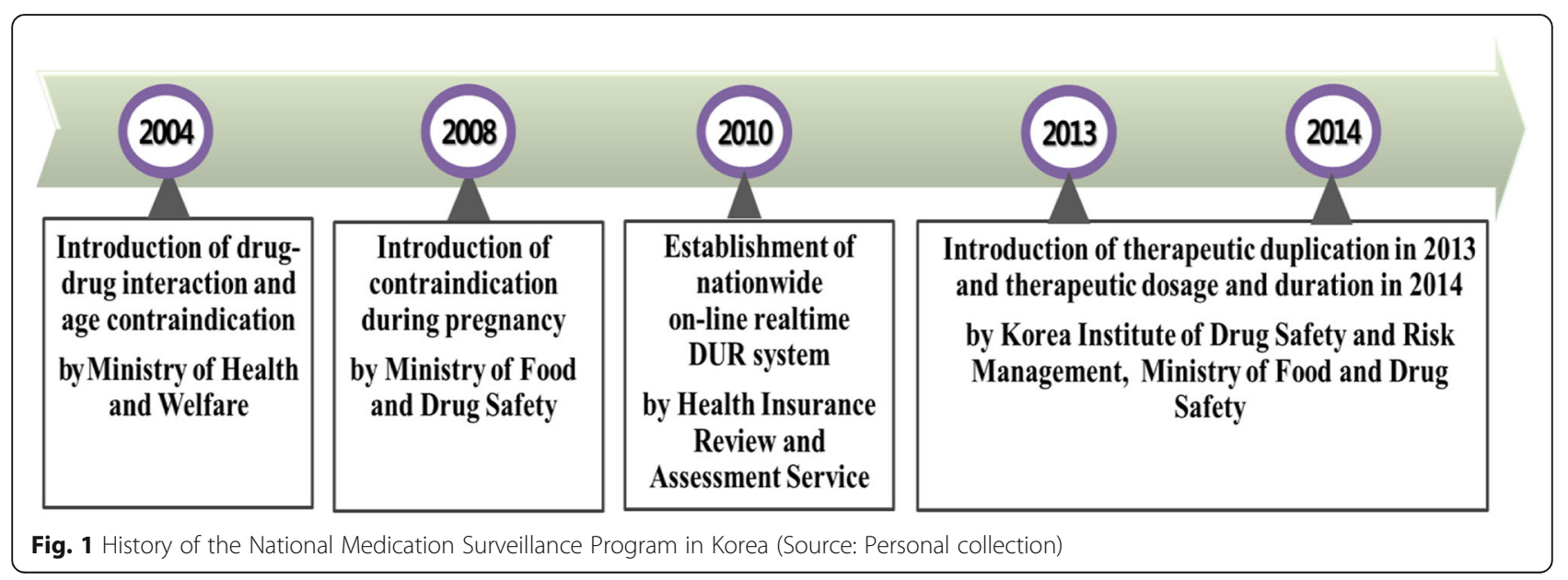


healthcare professionals. An initial draft of the questionnaire was pilot tested independently with 2 physicians and 5 pharmacists. After the test, we slightly modified the wording of some questions to improve the understanding of the respondents. The questions regarding the characteristics of study participants included profession (physician vs. pharmacist), gender, age, region, and years of practice. The level of satisfaction was collected using a 5-point scale: strongly satisfied, satisfied, neutral, dissatisfied, and strongly dissatisfied. Respondents were asked to rate, using the same scale, their opinions on whether the medication surveillance had made the following specific improvements: prevention of adverse drug reaction, decrease in therapeutic duplication, and decrease of drug overuse. The respondents then rated the degree to which the medication surveillance program was useful in their clinical practice for each information type (drug-drug interaction, age contraindication, pregnancy contraindication, and therapeutic duplication) on the same scale. The respondents were also asked to select the areas that most needed additional information among the following four types of the surveillance program services, which are provided by the US and European countries: cautionary information on patients with liver and renal disease, drug allergy cautionary information, clinical overuse and abuse, and gender-based cautionary information.

\section{Questionnaire administration}

The developed questionnaire was made accessible online on the KIDS's web-based survey system. We informed 167 organizations (158 academic societies under the Korean Academy of Medical Sciences and 9 physicianand pharmacist-related associations) of the survey webpage and solicited responses via phone calls and official letters from researchers from KIDS, a Korean public institute (May 22-27, 2014). All collaborating organizations sent e-mails, including a link to our survey system to their registered members or posted the link on their websites. After 3 weeks (June 10-13), we contacted the organizations with low response rates for further solicitation. Nonetheless, the response rate remained low, raising concerns regarding the lack of representativeness. Therefore, we conducted face-to-face interviews using printed questionnaires among participants at general academic congresses for hospital pharmacists and physicians. The survey was conducted from May 23 to August 11, 2014.

\section{Statistical analysis}

Data collected through face-to-face interviews were manually entered into a database, which was subsequently merged with the database constructed from the webbased survey. Questions were structured in a manner to collect categorical variables and calculate the frequency and percentage (\%). We calculated the frequency and percentage of responses according to the characteristics of study participants, such as profession, gender, age, region, years of practice, type of medical institution or pharmacy, and specialty (for physicians only). For the questions relating to the level of satisfaction with the medication surveillance program, whether the medication surveillance had resulted in specific improvements, and the degree to which each type of surveillance service improved clinical practice, we calculated the frequency by profession and performed a Pearson's chi-square test. To determine whether there was a difference between the opinions of physicians and pharmacists regarding additional medication surveillance services needed, we conducted a twosample $\mathrm{Z}$ test on the proportions of respondents who indicated each type of the additional medication surveillance service.

To identify the factors influencing the levels of satisfaction with the medication surveillance program, we conducted a multiple ordinal logistic regression analysis by adjusting for the characteristics of study participants (profession, gender, age, region, years of practice, type of medical institution or pharmacy, and specialty). To evaluate the representativeness of respondents, we performed a two-sample $\mathrm{Z}$ test on the proportions of physicians and pharmacists according to gender and region using demographic statistics of physicians and pharmacists. All statistical analyses were performed at the significance level of 0.05 using SAS 9.3 (SAS Institute Inc., Cary, NC, USA) [12, 13].

\section{Results}

The study population was comprised of 93,094 physicians and 32,572 pharmacists, who were the registered members of 167 organizations (158 academic societies under the Korean Academy of Medical Sciences and 9 physician- and pharmacist-related associations). We collected completed questionnaires from 1164 participants: 515 physicians (response rate, $0.55 \%), 634$ pharmacists (1.95\%), and 15 of unknown profession. Among the 1164 healthcare professionals, 508 responded to paper-based interviews and 656 to the web-survey. After excluding 44 respondents (12 physicians, 17 pharmacists, and 15 no answer) who failed to answer most of the questions, we analyzed data from 1120 respondents.

Out of a total of 1120 respondents, 503 were physicians (44.9\%), 617 pharmacists $(55.1 \%)$, and 579 males (51.7\%). The majority of the respondents were in their $30 \mathrm{~s}(39.0 \%)$ and $40 \mathrm{~s}(26.3 \%)$. The greatest proportion (26.6\%) of the respondents had practiced their respective profession for less than 5 years, whereas $22.3 \%$ had practiced for 20 years or longer. The 
greatest proportion of physicians worked at tertiary hospitals $(42.7 \%)$ and $41.2 \%$ of the pharmacists worked at hospital pharmacies. Most of the respondents (65.4\%) were located in the metro areas of Seoul, Gyeonggi, and
Incheon (Table 1). Seoul provided a disproportionately high proportion of respondents (Appendix 1).

Overall, $63.1 \%$ of all respondents were either strongly satisfied or satisfied with the medication surveillance

Table 1 Characteristics of survey respondents: physicians and pharmacists in South Korea

\begin{tabular}{|c|c|c|c|c|c|c|c|}
\hline$\frac{\text { Characteristics }}{\text { Gender }}$ & Total no. of respondents & (\%) & \multicolumn{2}{|c|}{ Physicians (\%) } & \multicolumn{2}{|c|}{ Pharmacists (\%) } & $\frac{p \text {-value }{ }^{*}}{<.0001}$ \\
\hline Male & 579 & $(51.7)$ & 366 & $(72.8)$ & 213 & $(34.5)$ & \\
\hline Female & 541 & $(48.3)$ & 137 & $(27.2)$ & 404 & (65.5) & \\
\hline Age (years) & & & & & & & $<.0001$ \\
\hline $20-29$ & 106 & $(9.5)$ & 25 & (5.0) & 81 & $(13.1)$ & \\
\hline $30-39$ & 437 & $(39.0)$ & 206 & $(41.0)$ & 231 & $(37.4)$ & \\
\hline $40-49$ & 294 & $(26.3)$ & 128 & $(25.4)$ & 166 & $(26.9)$ & \\
\hline $50-59$ & 180 & $(16.1)$ & 89 & $(17.7)$ & 91 & $(14.7)$ & \\
\hline $60+$ & 103 & $(9.2)$ & 55 & $(10.9)$ & 48 & (7.8) & \\
\hline Region & & & & & & & 0.04 \\
\hline Seoul & 475 & $(42.4)$ & 223 & $(44.3)$ & 252 & $(40.0)$ & \\
\hline Gyeonggi-do & 217 & (19.4) & 97 & $(19.3)$ & 120 & (19.4) & \\
\hline Incheon & 40 & (3.6) & 16 & $(3.2)$ & 24 & (3.9) & \\
\hline Gangwon-do & 29 & (2.6) & 12 & $(2.4)$ & 17 & (2.8) & \\
\hline Daejeon & 36 & (3.2) & 12 & $(2.4)$ & 24 & (3.9) & \\
\hline Chungcheongbuk-do & 20 & (1.8) & 16 & $(3.2)$ & 4 & $(0.6)$ & \\
\hline Chungcheongnam-do & 28 & $(2.5)$ & 17 & (3.4) & 11 & (1.8) & \\
\hline Gwangju & 18 & (1.6) & 8 & (1.6) & 10 & (1.6) & \\
\hline Jeollabuk-do & 31 & $(2.8)$ & 15 & (3.0) & 16 & (2.6) & \\
\hline Jeollanam-do & 21 & (1.9) & 8 & (1.6) & 13 & (2.1) & \\
\hline Daegu & 52 & $(4.6)$ & 18 & (3.6) & 34 & (5.5) & \\
\hline Ulsan & 16 & (1.4) & 5 & $(1.0)$ & 11 & (1.8) & \\
\hline Busan & 65 & (5.8) & 26 & $(5.2)$ & 39 & (6.3) & \\
\hline Gyeongsangbuk-do & 26 & (2.3) & 11 & $(2.2)$ & 15 & (2.4) & \\
\hline Gyeongsangnam-do & 36 & $(3.2)$ & 18 & (3.6) & 18 & (2.9) & \\
\hline Jeju & 10 & $(0.9)$ & 1 & $(0.2)$ & 9 & $(1.5)$ & \\
\hline Career (years) & & & & & & & 0.68 \\
\hline $0-4$ & 298 & $(26.6)$ & 126 & $(25.0)$ & 172 & $(27.9)$ & \\
\hline $5-9$ & 236 & $(21.1)$ & 98 & $(19.5)$ & 138 & (22.4) & \\
\hline $10-14$ & 193 & $(17.2)$ & 92 & (18.3) & 101 & $(16.4)$ & \\
\hline $15-19$ & 97 & (8.7) & 44 & (8.7) & 53 & (8.6) & \\
\hline $20+$ & 250 & $(22.3)$ & 114 & $(22.7)$ & 136 & (22.0) & \\
\hline Missing & 46 & $(4.1)$ & 29 & (5.8) & 17 & (2.8) & \\
\hline Hospital or Pharmacy type & & & & & & & $<.0001$ \\
\hline Tertiary hospital/ Hospital pharmacy & 469 & $(41.9)$ & 215 & $(42.7)$ & 254 & $(41.2)$ & \\
\hline Hospital/Pharmacy nearby hospital & 228 & $(20.4)$ & 68 & $(13.5)$ & 160 & (25.9) & \\
\hline Clinic/Community pharmacy & 366 & $(32.7)$ & 201 & $(40.0)$ & 165 & $(26.7)$ & \\
\hline Missing & 57 & $(5.0)$ & 19 & (3.8) & 38 & $(6.2)$ & \\
\hline Total & 1120 & $(100.0)$ & 503 & (44.9) & 617 & (55.1) & \\
\hline
\end{tabular}

${ }^{*} p$-value was calculated using chi-square test 
program (19.2 and 43.9\%, respectively). More pharmacists $(69.1 \%)$ were satisfied than were physicians (55.6\%). Among the respondents, $77.8 \%$ answered "agree" or "strongly agree" to the question regarding whether the surveillance program had decreased therapeutic duplication, and 63.8 and $63.3 \%$ of the respondents agreed that the surveillance program prevented ADRs and reduced drug overuse, respectively. Similar to the general satisfaction, more pharmacists were satisfied with the improvement conferred by the program than were physicians. The majority of members of both professions were satisfied with the decrease in therapeutic duplication $(73.4 \%$ of physicians and $81.4 \%$ of pharmacists). However, physicians' satisfaction (55.5\%) was considerably lower regarding the prevention of ADRs than that of pharmacists (70.6\%). The proportion of physicians satisfied with the decrease in drug overuse by physicians $(61.9 \%)$ was similar to that of pharmacists (64.4\%) (Table 2).

Pharmacists were more than two-times more likely to be satisfied with the medication surveillance program than were physicians [adjusted odds ratio (AOR), 2.13; 95\% confidence interval (CI), 1.65-2.76]. Respondents aged 60 years and older (AOR, 2.63; 95\% CI, 1.36-5.09) were more likely to be satisfied than were those in their 20s. Gender, region, and years of practice did not influence satisfaction levels (Table 3). Similarly, the clinical specialty of the physicians did not influence the satisfaction levels (Appendix 2).

Among the four types of medication surveillance services, the drug-drug interaction information was viewed as the most useful; 26.9 and $55.7 \%$ answered "agree" or "strongly agree," respectively, to the question regarding its usefulness, and $78.3 \%$ of physicians and $86.1 \%$ of pharmacists viewed the drug-drug interaction information as useful. Overall, 74.3, 72.5, and $69.3 \%$ viewed pregnancy contraindication, age contraindication, and therapeutic duplication, respectively, as useful; more pharmacists regarded these types of information to be more useful than did physicians (Table 4).

Cautionary information for patients with liver or renal diseases was identified as the medication surveillance service of greatest need; it was selected by $48.7 \%$ of all respondents (55.0\% of physicians, $43.7 \%$ of pharmacists), followed by drug-allergy caution information (33.8\%), drug abuse caution information (13.6\%), and gender caution information (3.9\%). When stratified by type of healthcare provider, the proportion of frequency was significantly different between physicians and pharmacists regarding safety information on liver or renal diseases and drug interactions $(55.0 \%$ vs. $43.7 \%)$ and clinical abuse or misuse $(10.6 \%$ vs. $16.0 \%)$ (Table 5).

\section{Discussion}

Difference in satisfaction between professions

Overall, $63.0 \%$ of the survey respondents were "satisfied" or "very satisfied" with the medication surveillance program, and a decrease in therapeutic duplication was regarded as a benefit of the medication surveillance by most respondents. However, the odds of being satisfied with the medication surveillance program were twotimes greater among pharmacists than among physicians, which suggests the need to improve factors

Table 2 Healthcare providers' satisfaction with the medication surveillance program in South Korea

\begin{tabular}{|c|c|c|c|c|c|c|}
\hline \multirow[t]{2}{*}{ Statement } & \multicolumn{5}{|l|}{ Frequency (\%) } & \multirow{2}{*}{$\begin{array}{l}p- \\
\text { value }\end{array}$} \\
\hline & Strongly unsatisfied & Unsatisfied & Neutral & Satisfied & Strongly satisfied & \\
\hline Are you satisfied with the medication surveillance? & $27(2.4)$ & $61(5.5)$ & $323(29.0)$ & $488(43.9)$ & $213(19.2)$ & $<0.001$ \\
\hline Physicians & $22(4.4)$ & $49(9.8)$ & $151(30.2)$ & $210(42.0)$ & $68(13.6)$ & \\
\hline Pharmacists & $5(0.8)$ & $12(2.0)$ & $172(28.1)$ & $278(45.4)$ & $145(23.7)$ & \\
\hline \multicolumn{7}{|c|}{ Do you think the medication surveillance has improved the following? } \\
\hline Prevention of adverse drug reactions & $21(1.9)$ & $103(9.3)$ & $278(25.0)$ & $468(42.1)$ & $241(21.7)$ & $<0.001$ \\
\hline Physicians & $19(3.8)$ & $70(14.1)$ & $133(26.7)$ & 197 (39.6) & 79 (15.9) & \\
\hline Pharmacists & $2(0.3)$ & $33(5.4)$ & $145(23.7)$ & $271(44.2)$ & $162(26.4)$ & \\
\hline Decrease in therapeutic duplication & $17(1.5)$ & $65(5.8)$ & $165(14.8)$ & $440(39.5)$ & $426(38.3)$ & $<0.001$ \\
\hline Physicians & $13(2.6)$ & $34(6.8)$ & $86(17.2)$ & $204(40.8)$ & $163(32.6)$ & \\
\hline Pharmacists & $4(0.7)$ & $31(5.1)$ & $79(12.9)$ & $236(38.5)$ & $263(42.9)$ & \\
\hline Decrease in drug overuse & $27(2.4)$ & $112(10.1)$ & $269(24.2)$ & $432(38.8)$ & $272(24.5)$ & $<0.001$ \\
\hline Physicians & $23(4.6)$ & $52(10.4)$ & $115(23.0)$ & $197(39.5)$ & $112(22.4)$ & \\
\hline Pharmacists & $4(0.7)$ & $60(9.8)$ & 154 (25.1) & 235 (38.3) & $160(26.1)$ & \\
\hline
\end{tabular}

${ }^{*} p$-value was calculated using chi-square test 
Table 3 Logistic regression model of factors associated with healthcare professionals' satisfaction with the medication surveillance program

\begin{tabular}{|c|c|c|}
\hline Independent variables & $\begin{array}{l}\text { OR ( } 95 \% \mathrm{Cl}) \\
\text { (modeling the likelihood of being classified into a higher } \\
\text { level of satisfaction) }\end{array}$ & $\begin{array}{l}\text { Adjusted OR }(95 \% \mathrm{Cl})^{\mathrm{a}} \\
\text { (modeling the likelihood of being classified into a higher } \\
\text { level of satisfaction) }\end{array}$ \\
\hline \multicolumn{3}{|l|}{ Profession } \\
\hline Physician & 1.00 & 1.00 \\
\hline Pharmacists & $2.02(1.62-2.52)$ & $2.13(1.65-2.76)$ \\
\hline \multicolumn{3}{|l|}{ Gender } \\
\hline Male & 1.00 & 1.00 \\
\hline Female & $1.07(0.87-1.33)$ & $1.00(0.77-1.31)$ \\
\hline \multicolumn{3}{|l|}{ Age (years) } \\
\hline $20-29$ & 1.00 & 1.00 \\
\hline $30-39$ & $0.94(0.64-1.39)$ & $1.18(0.75-1.87)$ \\
\hline $40-49$ & $1.03(0.68-1.55)$ & $1.04(0.61-1.76)$ \\
\hline $50-59$ & $1.63(1.05-2.55)$ & $1.72(0.93-3.17)$ \\
\hline $60+$ & $2.20(1.33-3.64)$ & $2.63(1.36-5.09)$ \\
\hline \multicolumn{3}{|l|}{ Region } \\
\hline Metropolitan & 1.00 & 1.00 \\
\hline City & $1.12(0.83-1.50)$ & $0.99(0.72-1.36)$ \\
\hline Rural & $1.16(0.87-1.54)$ & $1.07(0.78-1.47)$ \\
\hline \multicolumn{3}{|l|}{ Career (years) } \\
\hline$<5$ & 1.00 & 1.00 \\
\hline $5-9$ & $0.83(0.61-1.14)$ & $0.80(0.56-1.13)$ \\
\hline $10-14$ & $1.11(0.80-1.55)$ & $1.07(0.73-1.57)$ \\
\hline $15-19$ & $1.13(0.74-1.73)$ & $1.05(0.64-1.74)$ \\
\hline $20+$ & $1.56(1.14-2.12)$ & $1.06(0.68-1.66)$ \\
\hline \multicolumn{3}{|l|}{ Hospital or Pharmacy type } \\
\hline $\begin{array}{l}\text { Tertiary hospital/Hospital } \\
\text { pharmacy }\end{array}$ & 1.00 & 1.00 \\
\hline $\begin{array}{l}\text { Hospital/Pharmacy nearby } \\
\text { hospital }\end{array}$ & $1.85(1.38-2.49)$ & $1.62(1.18-2.21)$ \\
\hline Clinic/Community pharmacy & $1.33(1.03-1.71)$ & $1.22(0.92-1.61)$ \\
\hline
\end{tabular}

AOR Adjusted odds ratio, IC Confidence interval

${ }^{a}$ Adjusted for profession, gender, age, region, years of practice, type of medical institution or pharmacy, and specialty

hindering satisfaction with the medication surveillance program by considering the difference in the clinical status between the professions. While profession influenced the level of satisfaction with the surveillance program, the gender, region, and years of practice did not. Furthermore, profession influenced how the respondents felt about the improvements and clinical usefulness of the surveillance program. This finding may be attributable to differences in clinical characteristics, such as practice setting, the main types of service for which the medication surveillance program was used, and the types of relationships between physicians and pharmacists and their respective patients.
First, the observed differences between physicians and pharmacists may be caused by the fact that prescribing and dispensing occurred sequentially. In Korea, the medication surveillance program is provided via pop-up alerts through real-time checks of prescriptions at the stage of prescribing and dispensing. The physicians first access the surveillance program alerts when they prescribe medication, and the pharmacists access the alerts that the physicians leave unchecked. For that reason, the physicians and the pharmacists may feel differently about the amount and content of the alerts.

In addition, satisfaction level can be influenced by the fact that physicians and pharmacists focus on different 
Table 4 Usefulness of the medication surveillance program in a clinical setting per total respondents: physicians and pharmacists

\begin{tabular}{|c|c|c|c|c|c|c|}
\hline \multirow[t]{2}{*}{ Medication surveillance program } & \multicolumn{5}{|l|}{ Frequency (\%) } & \multirow{2}{*}{$\begin{array}{l}p- \\
\text { value }\end{array}$} \\
\hline & Very un-useful & Somewhat un-useful & Neutral & Somewhat useful & Very useful & \\
\hline Drug-drug interaction & $11(1.0)$ & $49(4.4)$ & $133(12.0)$ & $299(26.9)$ & $618(55.7)$ & $<0.001$ \\
\hline Physicians & $10(2.0)$ & $34(6.8)$ & $64(12.9)$ & $161(32.4)$ & $228(45.9)$ & \\
\hline Pharmacists & $1(0.2)$ & $15(2.4)$ & $69(11.3)$ & $138(22.5)$ & $390(63.6)$ & \\
\hline Age contraindication: Pediatric, Elderly & $20(1.8)$ & $59(5.3)$ & $226(20.4)$ & $361(32.5)$ & $444(40.0)$ & $<0.001$ \\
\hline Physicians & $17(3.4)$ & $39(7.8)$ & $129(26.0)$ & $166(33.4)$ & $146(29.4)$ & \\
\hline Pharmacists & $3(0.5)$ & $20(3.3)$ & $97(15.8)$ & $195(31.8)$ & $298(48.6)$ & \\
\hline Pregnancy contraindication & $28(2.5)$ & $58(5.2)$ & $198(17.9)$ & $295(26.7)$ & $526(47.6)$ & $<0.001$ \\
\hline Physicians & $24(4.9)$ & $38(7.7)$ & $101(20.4)$ & $143(28.9)$ & $188(38.1)$ & \\
\hline Pharmacists & $4(0.7)$ & $20(3.3)$ & $97(15.9)$ & $152(24.9)$ & $338(55.3)$ & \\
\hline Therapeutic duplication & $18(1.6)$ & $76(6.9)$ & $245(22.2)$ & $361(32.6)$ & $406(36.7)$ & $<0.001$ \\
\hline Physicians & $17(3.4)$ & $45(9.1)$ & $131(26.5)$ & $172(34.8)$ & $129(26.1)$ & \\
\hline Pharmacists & $1(0.2)$ & $31(5.1)$ & $114(18.6)$ & 189 (30.9) & $277(45.3)$ & \\
\hline
\end{tabular}

* $p$-value was calculated using chi-square test

areas in the process of prescribing and dispensing. Pharmacists focus on pharmacological treatment but prescribing by physicians is influenced by various factors, such as uncertainty associated with diagnosis, perception of patients' expectations, and need to maintain good physician-patient relationships [14, 15]. In the areas that need mutual collaboration, pharmacists want to identify and manage patients' drug-related problems, but physicians want to improve patients' adherence [16]. Because of the differences in the scope of roles and areas of focus, physicians and pharmacists might differently value the importance of alerts that provide information on drugs only, leading to the difference in levels of satisfaction.

Furthermore, different professionals may feel differently about medication surveillance alerts. The results showed that $73.4 \%$ of physicians and $81.4 \%$ of pharmacists (8.0\% difference) answered "agree" or "strongly agree" to the question regarding whether therapeutic duplication decreased through medication surveillance. This finding suggests that both physicians and pharmacists positively perceived the effect of the surveillance program on the reduction of therapeutic duplication because medications prescribed at another institution and dispensed at another pharmacy could frequently change. Nonetheless, a $15.1 \%$ difference was noted among professions who agreed that ADR prevention was a benefit of medication surveillance. Compared to pharmacists, highly specialized physicians deal with a limited scope of medications, and therefore, are more likely to receive alerts for which they already know the details and for which they perceive little value. This finding may have increased the inconvenience healthcare providers felt about the medication surveillance program, and thus, decreased their satisfaction with the surveillance regarding ADR prevention.

\section{Factors affecting satisfaction}

Our respondents, especially physicians, found age and pregnancy contraindication information to be less useful than the drug-drug interaction. Age and pregnancy contraindications are primarily based on the chemical structure of drugs and the results of animal studies because there are few clinical data.

Table 5 Additional safety information most needed per total respondents: physicians and pharmacists

\begin{tabular}{|c|c|c|c|c|c|c|c|}
\hline \multirow{3}{*}{$\begin{array}{l}\text { Safety information } \\
\text { Liver or kidney disease-drug interaction }\end{array}$} & \multicolumn{6}{|c|}{ Frequency (\%) } & \multirow{3}{*}{$\begin{array}{l}p^{-} \\
\text {value }^{*} \\
<0.001\end{array}$} \\
\hline & \multicolumn{2}{|l|}{ Total } & \multicolumn{2}{|c|}{ Physicians } & \multicolumn{2}{|c|}{ Pharmacists } & \\
\hline & 512 & $(48.7)$ & 255 & $(55.0)$ & 257 & $(43.7)$ & \\
\hline Drug allergy & 356 & $(33.8)$ & 147 & $(31.7)$ & 209 & (35.5) & 0.02 \\
\hline Clinical abuse, misuse & 143 & $(13.6)$ & 49 & $(10.6)$ & 94 & $(16.0)$ & $<0.001$ \\
\hline Precautions due to gender & 41 & (3.9) & 13 & $(2.8)$ & 28 & $(4.8)$ & 0.21 \\
\hline Total & 1052 & 100 & 464 & 100 & 588 & 100 & \\
\hline
\end{tabular}

* $p$-value was calculated using two-sample $Z$ test 
As previously mentioned, physicians consider satisfying patients' expectations regarding treatment, building trusting relationships, and clinical relevance of medicine. This suggests that they may have low levels of utilization and satisfaction with alerts that provide information based on pharmacological theories when prescribing for children and pregnant women.

Moreover, both physicians and pharmacists cited alert fatigue as the most important reason for their dissatisfaction with alerts. Alert fatigue may negatively influence the level of satisfaction with medication surveillance. Healthcare professionals receive the same age and pregnancy contraindication alerts as the patient's age or pregnancy status remains unchanged. In particular, physicians, who tend to see the same patient for a longer period of time than do pharmacists, may receive the same alerts over a longer period. This situation can be seen in the difference between the percentage of pharmacists and physicians who viewed age and pregnancy contraindication information as being clinically more useful (17.6 and 13.2\%, respectively) than the drug-drug interaction information (7.8\%).

To eliminate the factors negatively influencing satisfaction with the medication surveillance program, efforts to provide only clinically significant and highly effective surveillance services are needed through a revaluation of the effects on drug use and value of currently provided information. The US and European countries that have a longer history of implementing medication surveillance have experienced the alert fatigue phenomenon $[8,9]$. This fatigue may not only hinder tasks of physicians and pharmacists but may also lead them to be unaware of truly important alerts that need their attention. In an effort to solve the problem, the Netherlands strengthened the criteria for developing a drug database for the medication surveillance program by considering the effect $[11,17]$. This criterion was to provide only clinically meaningful and effective information that could prevent inappropriate drug use that was likely to recur through evaluating the potential effect of the surveillance program on behavioral change in prescribing and dispensing. Based on the literature review, drugdrug interaction was classified into five levels from no evidence to controlled, published interaction studies in patients or healthy volunteers, and clinically relevant endpoints according to the quality of scientific evidence. According to the severity level of specific clinical effects or toxicities of interactions, drug-drug interactions were classified on a 6-category scale from clinically irrelevant effects to multi-organ failure/ death. Following the classifications, a group of experts decided whether there were drug-drug interactions and a need for intervention through the electronic medical surveillance system. Experts selected only the information that had drug-drug interaction and required action. In addition, the Netherlands has improved the medication surveillance system in which the prescriber can control the repetition of alerts and revaluate the appropriateness of the existing drug database in the surveillance program.

\section{Current positive effect of the program and future needs}

Gender, region, and years of practice did not influence the level of satisfaction with medication surveillance, because the surveillance program in Korea was developed and disseminated under the leadership of the government and most healthcare professionals use the same software through the nationwide computerized medication surveillance system. Nonetheless, the respondents over 60 years of age were significantly associated with a higher level of satisfaction with the program (AOR, 2.63; 95\% CI, 1.36-5.09). This result is interesting considering the possibility that exposure to alerts for a long period of time could cause alert fatigue among healthcare professionals. However, there may be little difference in the duration of exposure between age groups in this study, in part because at the time of the survey, a long enough time has not passed since the implementation of the surveillance system. The higher level of satisfaction among older respondents may be attributed to the educational effect of the warning messages; recent pharmacological issues may be new to older physicians but not to recent medical graduates.

Another survey conducted among physicians and pharmacists before the establishment of the computerized medication surveillance system indicated that some of the healthcare professionals prescribed or dispensed contraindicated drugs because they did not know about the contraindication, emphasizing the need for a system that continuously checks drug information [18]. The current medication surveillance system was shown to reduce drug-drug interactions [19]. Consistent with findings of positive effects of medication surveillance program in other countries [20,21], our survey also showed that healthcare professionals cited reductions in therapeutic duplication, ADR, and drug overuse as the benefits of the medication surveillance system. These findings suggest the strengths of Korea's medication surveillance system that guarantees equitable access to the program services for most healthcare providers nationwide.

Despite the strengths, the medication surveillance system needs to be customized to meet the needs of individual patients to provide various kinds of information that are more helpful for patient safety and relevant in clinical practice. We identified the areas of 
high demand, such as cautionary information regarding patients with liver and renal diseases (43.7\%) and drug-allergy cautionary information (35.5\%). This type of information can be made available only if the surveillance system considers clinical information of individual patients, such as diagnosis, laboratory results, patient history, and medication history. Both the US and European countries provide a wider scope in the medication surveillance program that includes drug-allergy cautions, drug-disease cautions, and abuse/ overuse cautions $[8,9]$. Cautionary information for patients with renal disease was identified as the most useful of all types of medication surveillance services in the Netherlands where cautionary information is customized based on the renal function test of patients [22, 23]. To provide such diverse safety information, it is necessary to develop a system that collects patients' lab results, with their consent, and automatically checks their clinical information at the time of prescribing and dispensing. Implementation of this system will require an electronic medical record system, integration with the prescribing and dispensing system, and the patients' understanding and active participation in the medication surveillance program.

In our survey, some respondents answered the open-ended question and expressed their desire to retrieve additional information other than the items that we suggested, such as the list of drugs that the patients were currently taking, diagnoses, and medication history. This desire suggests that the current system of providing surveillance alerts on contraindications itself is not enough to be useful in clinical practice. Detailed information on contraindicated drugs was reported to be in high demand in other countries; information on side effects and the pharmacological mechanism are provided in the US and European countries [24]. Moreover, other countries have customized their medication surveillance systems to meet the needs of individual patients and established a system to share patient information among various healthcare providers; the US introduced E-prescribing systems and established the Web Portal Rx Hub by which healthcare providers can retrieve both patient history and prescription details. Since 2008, the Netherlands has a system that exchanges patient information [8, 22]. Korea also needs to establish a more effective and advanced medication surveillance system that is customizable to the needs of individual patients and healthcare professionals.

\section{Strengths and limitations}

This study diagnosed the status of the medication surveillance program, which has evolved over the past decade in Korea, by examining the level of satisfaction among healthcare providers with the current surveillance program and identified areas of additional needs for further development of the medication surveillance system. Despite its significance, this study had its limitations. Our sample may not represent the overall healthcare provider population. The respondents of our study were mainly in their 30s and 40s. This may be because younger respondents were more likely to be familiar with a web-based survey and sensitive to changes related to their work. The high representation of younger respondents could underestimate the overall level of satisfaction with the medication surveillance program, because respondents over 60 years of age were associated with higher levels of satisfaction in the logistic regression analysis. To mitigate the age-related selection bias, we additionally conducted face-to-face interviews to recruit older physicians; this attempt may contribute to the higher level of satisfaction with the program. Additionally, a substantial proportion of the respondents work in tertiary hospitals (42.7\%) and hospital pharmacies (41.2\%). These highly trained physicians and pharmacists may have been more interested in the medication surveillance program implemented by the government and, thus, participated in the survey more actively than did their peers in other settings. However, their special interest in the program or medicines does not guarantee their preferences or satisfaction with the program. The higher proportion of these respondents may not have affected the level of satisfaction. Rather, the lack of respondents working in hospitals or pharmacies near hospitals lead to underestimation of the level of satisfaction. These characteristics of our sample may hinder the generalizability of our findings. Future research should be conducted with respondents who are representative of the healthcare provider population in Korea, and thus, enhance the validity of the results of the study. In addition, as our study showed only clinical needs, future research needs to investigate factors influencing satisfaction.

\section{Conclusions}

The results of this study suggest that the current medication surveillance system should be improved by providing appropriate information that can be helpful depending on the interests and roles of physicians and pharmacists, as well as satisfying their clinical needs for additional information. Further development of the medication surveillance program should focus on clinically significant and useful information in practice through evaluating the effect of potential information on the behavioral change of healthcare providers rather than on a mere increase in information quantity. In addition, besides the clinical needs of physicians and pharmacists, future research needs to determine factors influencing satisfaction by profession. 


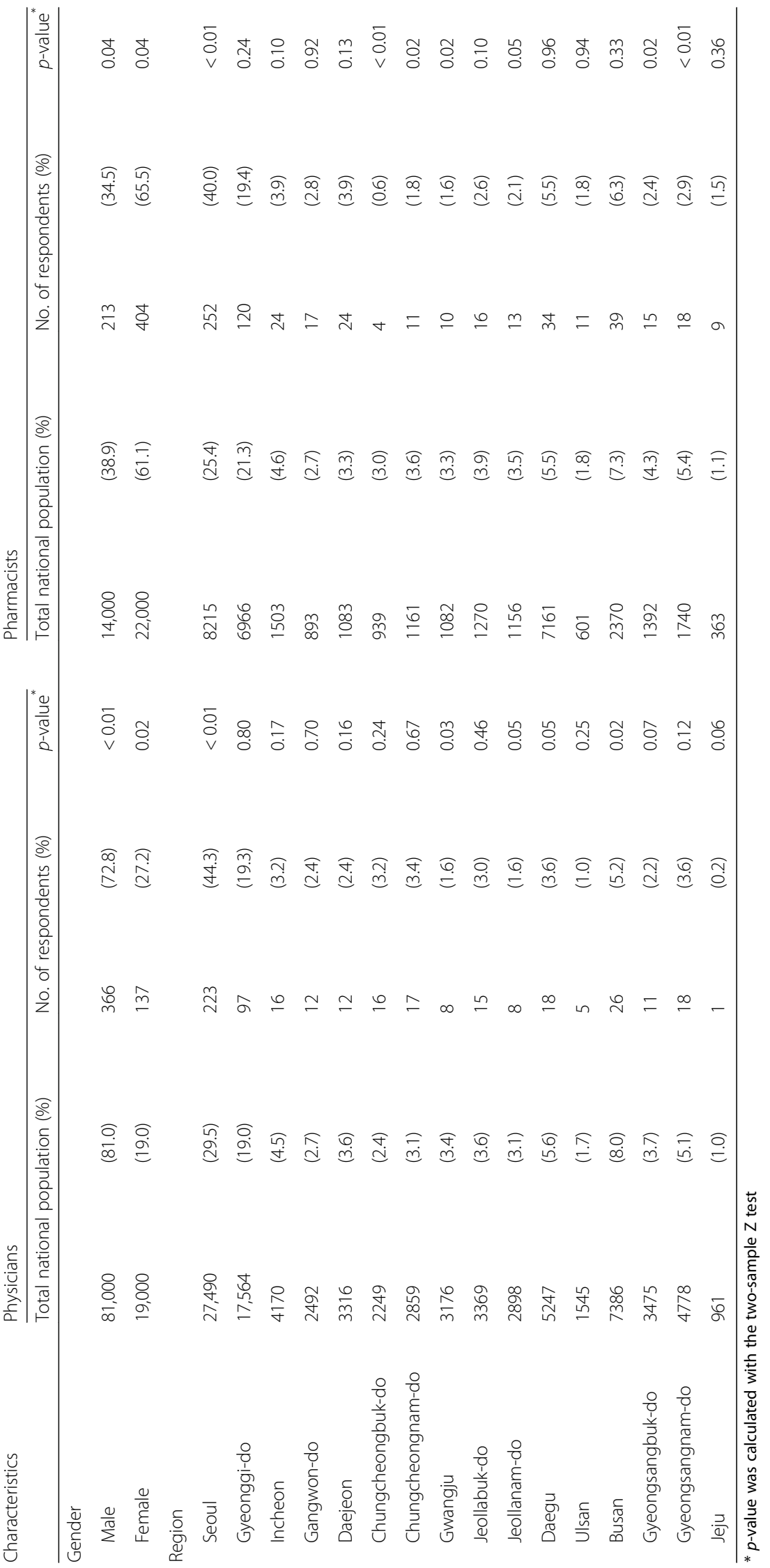




\section{Appendix 2}

Table $\mathbf{7}$ Logistic regression model of factors associated with healthcare professionals' satisfaction with the medication surveillance program

\begin{tabular}{|c|c|c|c|}
\hline Characteristics & Total no. of respondents ${ }^{a}$ & (\%) & $\begin{array}{l}\text { OR ( } 95 \% \text { Cl) (modeling the likelihood of being } \\
\text { classified into a higher level of satisfaction) }\end{array}$ \\
\hline \multicolumn{4}{|l|}{ Specialty } \\
\hline Family medicine & 53 & $(10.5)$ & 1.00 \\
\hline Internal medicine & 72 & $(14.3)$ & $1.16(0.60-0.22)$ \\
\hline Anesthesiology & 23 & $(4.6)$ & $0.69(0.28-1.70)$ \\
\hline Radiation oncology & 2 & $(0.4)$ & $0.37(0.03-4.83)$ \\
\hline Urology & 21 & $(4.2)$ & $1.41(0.55-3.59)$ \\
\hline Obstetrics \& Gynecology & 41 & $(8.2)$ & $0.70(0.33-1.48)$ \\
\hline Plastic surgery & 1 & $(0.2)$ & 34.62 (0.53 to > 999.99) \\
\hline Pediatrics \& Adolescent medicine & 29 & $(5.8)$ & $0.80(0.35-1.84)$ \\
\hline Neurology & 27 & $(5.4)$ & $0.27(0.12-0.63)$ \\
\hline Neurosurgery & 9 & (1.8) & $0.79(0.22-2.89)$ \\
\hline Ophthalmology & 4 & $(0.8)$ & $4.42(0.79-24.67)$ \\
\hline Radiology & 11 & $(2.2)$ & $2.95(0.88-9.94)$ \\
\hline Preventive Medicine & 1 & $(0.2)$ & $2.33(0.06-92.87)$ \\
\hline General surgery & 18 & (3.6) & $1.15(0.13-3.08)$ \\
\hline Emergency medicine & 7 & (1.4) & $0.78(0.18-3.28)$ \\
\hline Otorhinolaryngology & 25 & (5.0) & $0.45(0.19-1.09)$ \\
\hline Rehabilitation medicine & 15 & (3.0) & $1.09(0.38-3.12)$ \\
\hline Neuropsychiatry & 14 & $(2.8)$ & $1.22(0.41-3.62)$ \\
\hline Dentistry & 22 & $(4.4)$ & $2.09(0.83-5.27)$ \\
\hline Dermatology & 39 & (7.8) & $1.02(0.48-2.18)$ \\
\hline Thoracic \& Cardiovascular surgery & 5 & (1.0) & $0.82(0.15-4.38)$ \\
\hline Orthopedics & 12 & $(2.4)$ & $0.67(0.21-2.11)$ \\
\hline Others & 16 & (3.2) & $2.21(0.80-6.11)$ \\
\hline Missing & 36 & $(7.2)$ & \\
\hline Total & 503 & (100) & \\
\hline
\end{tabular}

Physicians may have two or more specialties

\section{Abbreviations}

ADRs: Adverse Drug Reactions; AOR: Adjusted Odds Ratio; Cl: Confidence Interval; KIDS: Korea Institute of Drug Safety and Risk Management; MFDS: Ministry of Food and Drug Safety

\section{Acknowledgements}

We would like to thank the Korea Institute of Drug Safety and Risk Management for their help conducting survey. We are also grateful for the support by MFDS (14172MFDS175). We thank Editage (www.editage.co.kr) for English proofreading.

\section{Authors' contributions}

All authors contributed to the study design and interpretation of data. JYS had the main responsibility for statistical analysis, but all authors contributed. HAK and JYS made substantial contributions to planning and conducting the survey. SMS and IS wrote the manuscript, and all authors reviewed and commented on drafts and approved the final manuscript and the decision to submit it for publication. HLJ contributed to critical revision of the manuscript. JYS is a guarantor, accepting full responsibility for the research, and SMS had access to the data and controlled the decision to publish. Moreover, all authors have participated sufficiently in the work to take public responsibility for the entire content of the manuscript. All authors have read and approved the final version of the manuscript.

\section{Funding}

No external funding was received for this study.

\section{Availability of data and materials}

The data used and/or analyzed in the study were used under agreement for the current study and are not publicly available.

\section{Ethics approval and consent to participate}

This study was approved by the Korea Institute of Drug Safety \& Risk Management Institutional Review Board (IRB No. 2014-1). Written informed consent for the use of anonymized data for scientific purposes was obtained from all responders in the study.

\section{Consent for publication}

Not applicable

\section{Competing interests}

The authors declare that they have no competing interests. 


\section{Author details}

'Korea Institute of Drug Safety and Risk Management, Anyang-si, Gyeonggi-do, South Korea. ${ }^{2}$ School of Pharmacy, Sungkyunkwan University, 2066, Seobu-ro, Jangan-gu, Suwon, Gyeonggi-do 16419, South Korea. ${ }^{3}$ College of Nursing and Health, Kongju National University, Gongju, South Korea.

Received: 9 September 2018 Accepted: 28 October 2019

Published online: 06 November 2019

\section{References}

1. Jeon HL, Park JH, Kim DS, Choi BC. Review of the drug utilization review program of United States 47 states and suggestion of policy. Health Soc Welf Rev. 2014;34:192-221.

2. Park BJ. Drug utilization review. J Pharmacoepidemiol Risk Manag. 2008;1:13-9.

3. Choi NK, Park BJ. Strategy for establishing an effective Korean drug utilization review system. J Korean Med Assoc. 2010;53:1130-8.

4. Academy of Managed Care Pharmacy (AMCP). Drug Utilization Review; 2019. Cited 2019 Sep 24. Available from: https://www.amcp.org/about/ managed-care-pharmacy-101/concepts-managed-care-pharmacy/drugutilization-review

5. Yi MH, Chung WJ, Cho E, Kim RE, Lee SM. Factors associated with changes in pharmaceutical expenditures of outpatient care in clinic setting: focusing on the incentive scheme to reduce total prescribed drug expenditure and the drug utilization review system. Korean J Health Policy Adm. 2012;22:561-78.

6. Chung SY, Jung SY, Shin JY, Park BJ. The role of KIDS for enhancing drug safety and risk management in Korea. J Korean Med Assoc. 2012;55:861-8.

7. Health Insurance Review and Assessment Service. Functions and roles of the Health Insurance Review and Assessment Service 2019; 2018. Cited 2019 Mar 11. Available from: http://www.hira.or.kr/co/ebook/list.do?pgmid= HIRAA030402000000/

8. Shin JY, Shin SM, Park BJ. Policy directions for the CMS DUR system in the USA. J Pharmacoepidemiol Risk Manag. 2013;6:87-92.

9. Park HJ, Shin JY, Shin SM, Park BJ. Current status of prospective DUR system running and retrospective DUR research in European countries. Korean Public Health Res. 2013;38(2):98-108.

10. Van der Sijs H, Aarts J, Van Gelder T, Berg M, Vulto A. Turning off frequently overridden drug alerts: limited opportunities for doing it safely. JAMIA. 2008; 15:439-48.

11. Landerdahl M. Overview of the utilisation of automated decision support tools at dispensing in the pharmacies in the European countries: University of Gothenburg; 2010.

12. Korean Statistical Information Service. Job statistics by sex. Daejeon: Statistics Korea; 2007. Cited 2015 Feb 6. Available from: http://kosis.kr/ statHtml/statHtml.do?orgld=101\&tblld=DT_1ES0611\&conn_path=13

13. Korean Statistical Information Service. Job statistics by region. Daejeon: Statistics Korea; 2014. Cited 2015 Feb 6. Available from: http://kosis.kr/ statHtml/statHtml.do?orgld=354\&tblld=DT_HIRA4T\&conn_path=I3

14. Wartman SA, Morlock LL, Malitz FE, Palm E. Impact of divergent evaluations by physicians and patients of patients' complaints. Public Health Rep. 1983; 98(2):141-5.

15. Chem ED, Anong DN, Akoachere JKT. Prescribing patterns and associated factors of antibiotic prescription in primary health care facilities of Kumbo east and Kumbo west health districts, North West Cameroon. PLoS One. 2018;13(3):e0193353.15.

16. Kelly DV, Bishop L, Young S, Hawboldt J, Phillips L, Keough TM. Pharmacist and physician views on collaborative practice: findings from the community pharmaceutical care project. Can Pharm J (Ott). 2013;146(4):218-26.

17. Jansman FG, Reyners $A K$, van Roon EN, Smorenburg CH, Helgason $\mathrm{HH}$, le Comte M, Wensveen BM, van den Tweel AM, de Blois M, Kwee W, Kerremans AL, Brouwers JR. Scientific Institute for Dutch Pharmacists (WINAp); Dutch Society for Medical Oncology (NVMO); Dutch Society of Clinical Pharmacology and Biopharmacy (NVKF\&B). Consensus-based evaluation of clinical significance and management of anticancer drug interactions. Clin Ther. 2011;33(3):305-14.

18. Shin JY, Lee AY, Shon SW, Choi NK, Shin SM, Park HJ, Park BJ. A survey of physicians and pharmacists regarding drug utilization review: prescribing and dispensing drugs with drug-drug interactions and age contraindications in Goyangsi. Korean Public Health Res. 2014;40(4):29-39.
19. Kim DS, Park JH, Jeon HR, Park CM, Kang HA. The effect of Korean prospective drug utilization review program on the prescription rate of drug-drug interactions. Korean J Health Policy Adm. 2014;24(2):120-7.

20. Kreling DH, Mott DA. The cost effectiveness of drug utilisation review in an outpatient setting. Pharmacoeconomics. 1993;4(6):414-36.

21. Bates DW, Leape LL, Cullen DJ, Laird N, Petersen LA, Teich JM, Burdick E, Hickey M, Kleefield S, Shea B, Vander Vliet M, Seger DL. Effect of computerized physician order entry and a team intervention on prevention of serious medication errors. JAMA. 1998;280(15):1311-6.

22. The KNMP Medication Safety Program. Hague, Netherlands: Royal Dutch Association for the advancement of Pharmacy; 2012. Cited 2018 Mar 20. Available from: http://www.fip.org/centennial/files/static/press/pressfiles/ Article/Article_on_MedicationSafety.docx.

23. Geerts AF, Scherpbier-de Haan ND, de Koning FH, van der Sterren TM, van Weel C, Vervoort GM, de Smet PA, de Grauw WJ. A pharmacy medication alert system based on renal function in older patients. Br J Gen Pract. 2012; 62(601):e525-9.

24. Bergk V, Gasse C, Schnell R, Haefeli WE. Requirements for a successful implementation of drug interaction information systems in general practice: results of a questionnaire survey in Germany. Eur J Clin Pharmacol. 2004;60:595-602.

\section{Publisher's Note}

Springer Nature remains neutral with regard to jurisdictional claims in published maps and institutional affiliations.
Ready to submit your research? Choose BMC and benefit from:

- fast, convenient online submission

- thorough peer review by experienced researchers in your field

- rapid publication on acceptance

- support for research data, including large and complex data types

- gold Open Access which fosters wider collaboration and increased citations

- maximum visibility for your research: over $100 \mathrm{M}$ website views per year

At BMC, research is always in progress.

Learn more biomedcentral.com/submissions 